\title{
2000-2019 Yılları Arasında Uzaktan Eğitimde Video Kullanımı Üzerine Yapılan Makalelerin İncelenmesi ${ }^{1}$
}

\author{
DOI: $10.26466 /$ opus. 864252
}

*

\author{
Asive Ata * - Melike Arslan ** \\ * Dr. Öğr. Üyesi, Atatürk Üniversitesi Açıöğretim Fakültesi, Erzurum/Türkiye \\ E-Posta: asiye.ata@atauni.edu.tr \\ ORCID: $\underline{0000-0001-7862-7872}$ \\ ** Doç. Dr. Atatürk Üniversitesi Açıköğretim Fakültesi, Erzurum/Türkiye \\ E-Posta: melikeaydemir@atauni.edu.tr \\ ORCID: 0000-0002-5899-2175
}

\section{Öz}

Bu çalışma uzaktan eğitimde öğretimsel materyal olarak kullanılan video üzerine odaklanmaktadır. Çalışmanın amacı 2000-2019 yılları arasında SSCI kapsamındaki dergilerde yayımlanmış uzaktan eğitimde video kullanımı üzerine yapılan araştırmaların tanımlayıcı, yöntemsel ve genel eğilimlerini ortaya çıkarmaktır. Çalışma kapsamında araştırmaların yayımlandı̆̆ı yıllar, yöntemleri, veri toplama araçları, örneklem türü ve örneklem sayılarına odaklanılmıştır. Bunun için Web of Science veri tabanında konusu uzaktan eğitim ve video, yıl aralı̆̆ 2000-2019, indexi SSCI olan makaleler aranmış ve seçilmiştir. Bu doğrultuda 226 makale bulunmuştur. Bu makaleleri analiz etmek için yayın sınıflama formu geliştirilmiştir. Elde edilen veriler betimsel istatistiki yöntemler kullanılarak analiz edilmiştir. Bulgulara göre uzaktan eğitimde video kullanımı üzerine yapılan makalelerin son yıllarda araştırma

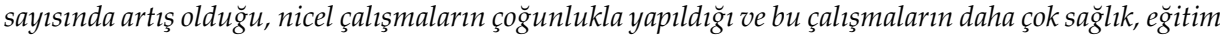
ve mühendislik alanlarında, nitel çalışmalarda da daha çok sosyal beşeri, güzel sanatlar, hukuk alanlarında yapıldı̆̆ı tespit edilmiştir. Veri toplama aracı olarak en çok anketin kullanıldığı ve örneklem türleri dağılımında da en çok öğrencilerin tercih edildiği görülmektedir. Uzaktan eğitim alanında video kullanımına yönelik yapılan araştırmalardaki alanlardaki örneklem türlerinin dağılımı incelendiğinde en çok eğitim alanında sonrasında da sağhlk alanında olduğu tespit edilmiştir. Örneklem sayılar dağ̆llımında ise örneklem sayısı olarak en çok 31-100 arasının tercih edildiği görülmektedir. Ayrıca çalışma kapsamında örneklem sayılarının dağılımında ise en çok sağlık alanında araştırmaların yapıldığı sonucuna ulaşılmıştır.

Anahtar Kelimeler: Uzaktan Ĕ̆itim,Video, Araştırma Ĕ̆ilimleri, Betimsel Analiz, Dijital İletişim

\footnotetext{
${ }^{1}$ Bu çalışmanın ön bulguları The $2^{\text {nd }}$ International Conference on Distance Learning and Innovative Educational Technologies'te sözlü bildiri olarak sunulmuştur.
} 


\title{
A Review of Articles on Video Usage in Distance Education between 2000 and 2019
}

\begin{abstract}
This study focuses on video used as instructional material in distance education. The aim of this study is to reveal the descriptive, methodological and general trends of the researches on the use of video in distance education published in journals covered by SSCI between 2000 and 2019. Within the scope of the study, the years in which the studies were published, their methods, data collection tools, sample type and sample numbers were focused on. For this, articles with distance education and video, year range 2000-2019, index SSCI were searched and selected in the Web of Science database. Accordingly, 226 articles were found. A publication classification form was developed to analyze these articles. The obtained data were analyzed using descriptive statistical methods. According to the findings, it has been determined that the number of researches on the use of video in distance education has increased in recent years, quantitative studies are mostly conducted and these studies are mostly conducted in the fields of health, education, and engineering, and qualitative studies, are mostly conducted in the fields of social humanities, fine arts, and law. It is seen that the questionnaire was used the most as the data collection tool and students were the most preferred sample types. When the distribution of the sample types in the researches on the use of video in the field of distance education was examined, it was found that it was mostly in the field of education and then in the field of health. In the distribution of sample numbers, it is seen that 31-100 was preferred. In addition, according to the distribution of sample numbers, it was concluded that researches were mostly conducted in the field of health.
\end{abstract}

Keywords: Distance education, Video, Research Trends, Descriptive Analysis, Digital Communication 


\section{Giriş}

Öğretim süreçlerinde çeşitli metin, grafik/resim, ses ve video teknolojileri öğrencinin öğrenmeye olan ilgisini artırmaya yönelik materyallerdir. Görüntü, uzaktan eğitimde öğretim bilgisini aktarma ve taşımayı gerçekleştiren bir eğitim içeriğidir. Zengin ve renkli resimlerle birlikte görüntüler öğrencinin öğrenmesine yardımcı olur ve canlılık katar (Ma, 2019). Görsel işitsel araçlar, öğrencilerin anlama düzeylerini artırmak için çoklu ortam sunumları aracılığıyla oluşan teknolojilerdir (Garzon, 2012). Çoklu ortam ve iletişim teknolojilerindeki son gelişmelerde en güçlü öğrenme sistemlerinden biri de videolardır. Video, e-öğrenmede zengin ve güçlü bir araçtır. Bilgiyi cazip ve çekici bir şekilde sunabilir (Zhang, Zhou, Briggs ve Nunamaker, 2005). Eski bir klişede olduğu gibi: “Bir görüntü bin kelimeye bedeldir." sözüne istinaden hareketli görüntüler eklemek; öğrenme bağlamında özgünlük, gerçeklik ve dersin içeriğine canlılık getirebilir. Hareketli görüntü bir yüzyıl önce büyülü fenerlerden başlayarak son web teknolojileriyle günümüzde eğitimin de bir özelliği olmuştur. Bir yüzyıl boyunca, hareketli görüntü teknolojilerinin birbirini izlediği ve film, televizyon, videoteyp, video disk, dijital masaüstü video, çoklu ortam, CD-ROM, video konferans, interaktif TV ve şimdi de web-tabanlı medya olarak geliştiği görülmektedir. Eğitimde görselliğin önemiyle birlikte kaynağa daha kolay ve daha rahat ulaşma düşüncesi de bulunmakta (Bijnens, Vanbuel, Verstegen ve Young, 2004) özellikle online öğrenmede video bu kaynaklardan biri olmaktadır.

Dabbagh (2005), online öğrenme geliştiricilerinin daha gerçekçi olmak için resim, grafik, dijital ses ve video kullandığına vurgu yapar. Online öğrenme kaynağı olan açık ve uzaktan eğitimde önemli bir materyal olan videolar dijital çă̆ açısından öğrenmede gerçekleştirilen görsel materyallerden biridir. Abeysekera ve Dawson'a göre (2014), kayıtlı ya da çevrimiçi video dersler, bilgisayar teknolojisi ve internetin kullanımıyla geleneksel dersleri bilgi iletimi zamanının dışına taşıyarak aktif öğrenmeyi geliştiren materyallerden biri olmuştur.

Bilgi ve iletişim teknolojilerinin ilerlemesi, telekomünikasyon, ticaret, medya ve eğitim gibi endüstrileri de etkilemektedir. Uzaktan eğitim de geleneksel eğitim sistemine paralel çalışan zorlu ve bir o kadar da popüler bir eğitim sistemidir. Bu popülerliğin ardındaki sebep, zaman ve mekâna 
göre çalışma esnekliğinin olmasıdır. Uzaktan eğitimin ana kaynaklarından biri olan videolar (Singh, Nag, Karforma ve Mukhopadhyay, 2019), metinlerin yanı sıra kullanılan görüntüsel unsur olarak öğrenenlere görsel ve işitsel olanaklar sunar. Bazı öğrencilerin görsel olarak öğrenmeleri daha hızlı gerçekleşebilmektedir (Eryılmaz ve Jaballa, 2019). Eğitimde teknolojinin kullanımı sayesinde öğrenme ve öğretme faaliyetlerinin ve ortamlarının etkilendiği dolayısıyla öğrenenlerin bireysel olarak gelişimine de katkı sağlandı̆̆ı söylenebilmektedir (Yılmaz ve Üredi, 2020).

21. yüzyıl küresel olarak teknoloji destekli öğrenmenin yüzyılı olarak görülmektedir. Videolar ilköğretim kademesinden yükseköğrenime hatta günlük hayatta da başvurulan önemli öğretici kaynaklar olarak görülmektedir. Bilgisayar ve İnternete erişimi olan herkesin yararlandiğı bu kaynaklar görsel-işitsel ve öğretimsel özelliklerinin yanı sıra kolay erişim, hız ve zaman-mekân esnekliği gibi özellikleri ile de cazip hale gelebilmektedirler. Uzaktan eğitimde kullanılan görüntüsel unsur olan videoların incelendiği bu çalışmada 2000-2019 yılları arasında SSCI kapsamındaki dergilerde yayımlanmış uzaktan eğitimde video kullanımı üzerine yapılan araştırmalar incelenmiştir. Çalışma kapsamında araştırmaların konuları, video kullanım amacı, hangi tür videolar kullanımı ve yayımlandığı yıllara odaklanılmıştır.

\section{Araştırma Amacı ve Soruları}

Bu çalışmanın amacı 2000-2019 yılları arasında SSCI kapsamındaki dergilerde yayımlanmış uzaktan eğitimde video kullanımı üzerine yapılan araştırmaların tanımlayıcı, yöntemsel ve genel eğilimlerini ortaya çıkarmaktır. Bu amaç kapsamında aşağıdaki araştırma sorularına cevap aranmiştır.

Uzaktan eğitim alanında video kullanımına yönelik 2000-2019 yılları arasında yayınlanmış makalelerin;

1. Yıllara göre dağılımı nasıldır?

2. Araştırma alanlarında kullanılan yöntemlerin dağılımı nasıldır?

3. Araştırma alanlarındaki veri toplama araçlarının dağılımı nasıldir?

4. Araştırma alanlarındaki örneklem türü ve örneklem sayılarının dağılımı nasıldır? 
Çalışma kapsamında araştırmaların konuları, video kullanım amacı, hangi tür videolar kullanımı ve yayımlandığı yıllara odaklanılmıştır.

\section{Yöntem}

Çalışmada uzaktan eğitimde video kullanımına yönelik genel eğilimleri ortaya çıkarmak amacıyla içerik analizi yöntemi kullanılmıştır. İçerik analizinde benzer veriler belirli terimler ve kavramlar temelinde birleştirilerek çalışmanın amacına uygun olacak ve anlaşılır hale gelecek şekilde aktarılmaktadır (Yıldırım ve Şimşek, 2006). Bu çalışmada da 2000-2019 yılları arasında SSCI kapsamındaki dergilerde yayımlanmış uzaktan eğitimde video kullanımı üzerine yapılan araştırmaların tanımlayıcı, yöntemsel ve yayımlandığı yıllara yönelik verileri analiz edilip aktarılmıştır.

\section{Örneklem}

Çalışmada uzaktan eğitimde video kullanımına yönelik makalelere odaklanılmıştır. Makalelere ulaşmak için "Web Of Science" veri tabanında "uzaktan eğitim" ve "video" kelimesi geçen konu odaklı arama yapılmıştır. Aramada yıl aralığ 1 2000-2019 olarak belirlenmiş ve atıf indekslerinden Social Science Citation Index (SSCI) seçilmiştir. Arama sonucunda 338 çalışma listelenmiştir. Sadece makaleler ele alınınca çalışma sayısı 323'e düşmüştür. Bu makalelerden 27'sinin tam metnine ulaşılamadığından 296 makale kalmıştır. Makaleler incelenirken 70 çalışmanın da uzaktan eğitimde video kullanımına yönelik olmadığ tespit edilmiştir. 226 makale üzerinden analizler gerçekleştirilmiştir.

\section{Veri Toplama Araci}

Çalışmada Eğitim Teknolojileri Sınıflama Formu'nda (Göktaş vd. 2012) yer alan yöntem, örneklem sayısı bölümleri alınmış ve araştırma amacı kapsamında tanımlayıcı bilgiler, araştırma alanı ve örneklem bölümleri eklenmiş ve çalışmaya özgü form oluşturulmuştur. 


\section{Veri Analizi}

Çalışma amacı doğrultusunda makalelerin yılı, araştırma alanları, yöntemi, veri toplama araçları, örneklem türü ve örneklem sayısı temelinde analizler gerçekleştirilmiştir. Bu doğrultuda veriler betimleyici istatistiki yöntemler kullanılarak sunulmuştur.

\section{Bulgular}

\section{Yıllara göre dağılım}

Uzaktan eğitimde video kullanımına yönelik yapılan araştırmaları oluşturan makaleler 2000-2019 yılları arasında ele alınmıştır. Bu yıllara göre makale sayısı dağılımı Grafik 1'de gösterilmiştir.

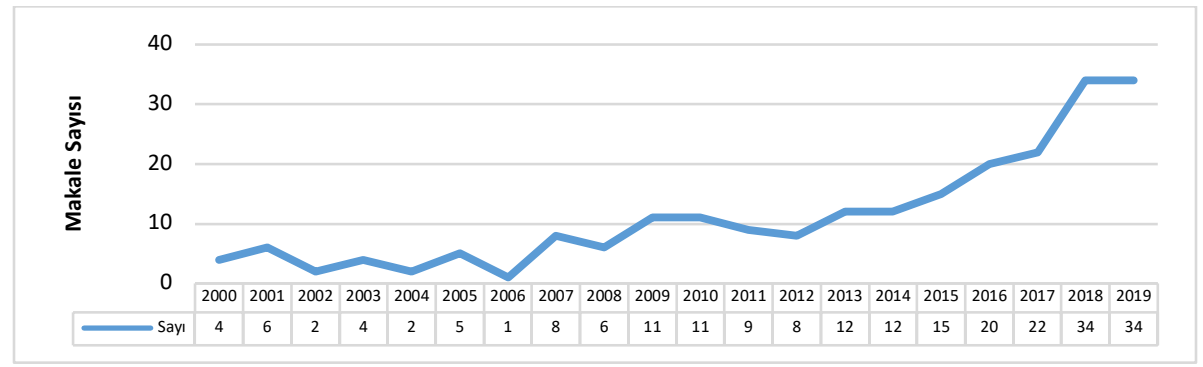

Grafik 1. Makalelerin yıllara göre dağıllımı

Grafik 1 incelendiğinde son 5 yılda uzaktan eğitimde video kullanımı üzerine yapılan çalışmaların arttığı gözlenmiştir. En az yayının 2006 y1lında en çok yayının ise 2018 ve 2019 yılında yapıldığı görülmektedir.

\section{Araştırma Alanlarında Kullanılan Yöntemlerin Dağılımı}

Uzaktan eğitimde video kullanımına yönelik yapılan araştırmalardaki alanlarda kullanılan yöntemlerin dağılımı incelenmiştir. Araştırma alanlarında kullanılan yöntemlerin makale sayısına göre dağılımı Tablo 1'de gösterilmiştir. 
Tablo 1. Araştırma alanlarında kullanılan yöntemlerin dağılımı

\begin{tabular}{lllllllllll}
\hline \multirow{2}{*}{ Alan } & \multicolumn{3}{l}{ Nicel } & \multicolumn{3}{c}{ Nitel } & \multicolumn{3}{c}{ Karma } & \multicolumn{3}{c}{ Alan yazın } & \multicolumn{2}{c}{ Toplam } \\
& $\mathrm{N}$ & $\%$ & $\mathrm{~N}$ & $\%$ & $\mathrm{~N}$ & $\%$ & $\mathrm{~N}$ & $\%$ & N & $\%$ \\
\hline Eğitim & 45 & 19.91 & 35 & 15.49 & 17 & 7.52 & 11 & 4.87 & 108 & 47.79 \\
Sağllk & 55 & 24.34 & 17 & 7.52 & 7 & 3.10 & 6 & 2.65 & 85 & 37.61 \\
Sosyal Beşeri & 4 & 1.77 & 6 & 2.65 & - & - & - & - & 10 & 4.42 \\
Mühendislik & 5 & 2.21 & 2 & 0.88 & - & - & - & - & 7 & 3.10 \\
Dil Bilimi & 2 & 0.88 & 2 & 0.88 & 1 & 0.44 & - & - & 5 & 2.21 \\
Güzel sanatlar & - & - & 4 & 1.77 & - & - & - & - & 4 & 1.77 \\
Spor & 1 & 0.44 & 1 & 0.44 & 1 & 0.44 & - & - & 3 & 1.33 \\
Hukuk & 1 & 0.44 & 2 & 0.88 & - & - & - & - & 3 & 1.33 \\
Din Bilimi & - & - & - & - & 1 & 0.44 & - & - & 1 & 0.44 \\
Toplam & 113 & 50.00 & 69 & 30.53 & 27 & 11.95 & 17 & 7.52 & & \\
\hline
\end{tabular}

Tablo 1 incelendiğinde uzaktan eğitim alanında video kullanımı daha çok bir konunun anlatımında kullanıldığı eğitim alanında yapılmıştır (\%47.79). Bu alanı sağlık (\%37.61) ve sosyal beşeri (\%4.42) alanlar takip etmiştir. En az yayının ise spor (\%1.33), hukuk (\%1.33) ve din bilimi (\%0.44) alanlarında yapıldığı görülmektedir.

Tablo 1 incelendiğinde uzaktan eğitim alanında video kullanımına yönelik araştırmalarda daha çok nicel yöntemler tercih edilmiştir (\%50.00). Bunu sirasıyla nitel yöntemler (\%30.53), karma yöntemler (\%11.95) ve alan yazın (\%7.52) takip etmiştir.

Tablo 1 incelendiğinde uzaktan eğitim alanında video kullanımına yönelik yapılan araştırmalardaki alanlarda kullanılan yöntemlerin dağılımı incelendiğinde sağlık alanında nicel çalışma sayısının en fazla olduğu (\%24.34) görülmüştür. Tüm alanlar incelendiğinde sağlık alanının yanı sıra (\%24.34), eğitim (\%19.91) ve mühendislik (\%2.21) alanlarında daha çok nicel çalışmaların yapıldığı görülmüştür. Sosyal beşeri (\%2.65), güzel sanatlar (\%1.77), hukuk (\%0.88) alanlarında ise daha çok nitel çalışmalar yapıldığ 1 tespit edilmiştir. Dil bilimi alanında nicel (\%0.88) ve nitel (\%0.88) yöntemli çalışmaların eşit ağırlıkta yapıldığı, din bilimi alanında ise sadece karma araştırma yönteminin (\%0.44) kullanıldığ1 görülmüştür. 


\section{Araştırma Alanlarında Kullanılan Veri Toplama Araçlarının Dağı- limı}

Uzaktan eğitimde video kullanımına yönelik yapılan araştırmalardaki alanlarda kullanılan veri toplama araçlarının dağılımı incelenmiştir. Araştırma alanlarında kullanılan veri toplama araçlarının sayısına göre dağılımı Tablo 2'de gösterilmiştir.

Tablo 2. Araştırma alanlarında kullanılan veri toplama araçlarının dağılımı

\begin{tabular}{|c|c|c|c|c|c|c|c|c|c|c|c|c|}
\hline \multirow[t]{2}{*}{ Alan } & \multicolumn{2}{|c|}{ Anket } & \multicolumn{2}{|c|}{ Doküman } & \multicolumn{2}{|c|}{ Görüşme } & \multicolumn{2}{|c|}{$\begin{array}{l}\text { Tutum öl- } \\
\text { çeği }\end{array}$} & \multicolumn{2}{|c|}{$\begin{array}{l}\text { Başarı } \\
\text { testi }\end{array}$} & \multicolumn{2}{|c|}{ Gözlem } \\
\hline & $\mathrm{N}$ & $\%$ & $\mathrm{~N}$ & $\%$ & $\mathrm{~N}$ & $\%$ & $\mathrm{~N}$ & $\%$ & $\mathrm{~N}$ & $\%$ & $\mathrm{~N}$ & $\%$ \\
\hline Eğitim & 44 & 19.47 & 26 & 11.50 & 25 & 11.06 & 19 & 8.41 & 11 & 4.87 & 10 & 4.42 \\
\hline Sağllk & 35 & 15.49 & 14 & 6.19 & 11 & 4.87 & 19 & 8.41 & 12 & 5.31 & 3 & 1.33 \\
\hline Sosyal Beşeri & 1 & 0.44 & 4 & 1.77 & 4 & 1.77 & 2 & 0.88 & - & - & 2 & 0.88 \\
\hline Mühendislik & 4 & 1.77 & 2 & 0.44 & - & - & 1 & 0.44 & 1 & 0.44 & - & - \\
\hline Dil Bilimi & 2 & 0.88 & 2 & 0.88 & 1 & 0.44 & - & - & - & - & - & - \\
\hline Güzel sanatlar & - & - & 3 & 1.33 & 2 & 0.88 & - & - & - & - & 1 & 0.44 \\
\hline Spor & - & - & - & - & 2 & 0.88 & - & - & 2 & 0.88 & - & - \\
\hline Hukuk & 2 & 0.88 & 1 & 0.44 & 1 & 0.44 & - & - & - & - & - & - \\
\hline Din Bilimi & - & - & - & - & 1 & 0.44 & 1 & 0.44 & - & - & - & - \\
\hline Toplam & 88 & 38.94 & 52 & 23.01 & 47 & 20.80 & 42 & 18.58 & 26 & 11.50 & 16 & 7.08 \\
\hline
\end{tabular}

Tablo 2 incelendiğinde uzaktan eğitim alanında video kullanımına yönelik araştırmalarda veri toplama aracı olarak en çok anket kullanılmıştır (\%38.94). Bunu sırasıyla doküman (\%23.01), görüşme (\%20.80), tutum ölçeği (\%18.58), ve başarı testi (\%11.50) takip etmiştir. En az kullanılan veri toplama aracının ise gözlem (\%7.08) olduğu tespit edilmiştir.

Tablo 2 incelendiğinde uzaktan eğitim alanında video kullanımına yönelik yapılan araştırmalardaki alanlarda kullanılan veri toplama araçlarının dağılımı incelendiğinde eğitim (\%19.47), sağlık (\%15.49), mühendislik (\%1.77) ve hukuk (\%0.88) alanında en çok anketin tercih edildiği görülmüştür. Sosyal beşeri alanda en çok doküman (\%1.77) ve görüşmenin (\%1.77) kullanıldığı, dil biliminde en çok anket (\%0.88) ve dokümanın (\%0.88) kullanıldığı, güzel sanatlarda en çok dokümanın (\%1.33) kullanıldığı spor alanında en çok görüşme (\%0.88) ve başarı testinin (\%0.88) kullanıldığ1 ve din bilimi alanında ise en çok görüşme (\%0.44) ve tutum ölçe- 
ğinin (\%0.44) kullanıldığı görülmüştür. Mühendislik alanı hariç tüm alanlarda görüşmenin kullanıldığı tespit edilmiştir. Başarı testi ve gözlemin ise alan çeşitliliği bakımından en az alanda kullanıldığı tespit edilmiştir.

\section{Araştırma Alanlarındaki Örneklem Türleri ve Örneklem Sayılarının Dağılımı}

Uzaktan eğitimde video kullanımına yönelik yapılan araştırma alanlarındaki örneklem türleri ve örneklem sayılarının dağılımı incelenmiştir. Araştırma alanlarındaki örneklem türlerinin dağılımı Tablo 3'te ve örneklem sayılarının dağılımı ise Tablo 4'te gösterilmiştir.

Tablo 3. Araştırma alanlarındaki örneklem türlerinin dağılımı

\begin{tabular}{lllllllllll}
\hline & \multicolumn{1}{l}{ Öğrenci } & \multicolumn{3}{c}{ Doküman } & \multicolumn{2}{l}{ Halk } & \multicolumn{3}{c}{ Öğretmen } & \multicolumn{2}{c}{$\begin{array}{l}\text { Sağlık Çalı- } \\
\text { şanı }\end{array}$} \\
\cline { 2 - 12 } Alan & $\mathrm{N}$ & $\%$ & $\mathrm{~N}$ & $\%$ & $\mathrm{~N}$ & $\%$ & $\mathrm{~N}$ & $\%$ & $\mathrm{~N}$ & $\%$ \\
\hline Eğitim & 75 & 33.19 & 15 & 6.64 & 4 & 1.77 & 16 & 7.08 & - & - \\
Sağlık & 42 & 18.58 & 7 & 3.10 & 18 & 7.96 & - & - & 22 & 9.73 \\
Sosyal Beşeri & 5 & 2.21 & 5 & 2.21 & 3 & 1.33 & 1 & 0.44 & - & - \\
Mühendislik & 7 & 3.10 & - & - & - & - & - & - & - & - \\
Dil Bilimi & 2 & 0.88 & - & - & 1 & 0.44 & 2 & 0.88 & - & - \\
Güzel sanatlar & 3 & 1.33 & 1 & 0.44 & - & - & 3 & 1.33 & - & - \\
Spor & 1 & 0.44 & - & - & 2 & 0.88 & - & - & - & - \\
Hukuk & 2 & 0.88 & 1 & 0.44 & - & - & - & - & - & - \\
Din Bilimi & 2 & 0.88 & - & - & - & - & - & - & - & - \\
Toplam & 138 & 61.06 & 29 & 12.83 & 28 & 12.39 & 22 & 9.73 & 22 & 9.73 \\
\hline
\end{tabular}

Tablo 3 incelendiğinde uzaktan eğitim alanında video kullanımına yönelik araştırmalarda örneklem türü olarak en çok öğrenciler (\%61.06) tercih edilmiştir. Bunu sırasıyla doküman (\%12.83), halk (\%12.39), öğretmen (\%9.73) ve sağlık çalışanı (\%9.73) takip etmiştir.

Tablo 3 incelendiğinde uzaktan eğitim alanında video kullanımına yönelik yapılan araştırmalardaki alanlardaki örneklem türlerinin dağıllmında eğitim (\%33.19), sağlık (\%18.58), mühendislik (\%3.10), hukuk $(\% 0.88)$ ve din bilimi (\%0.88) alanında en çok öğrencilerin tercih edildiği görülmüştür. Sosyal beşeri alanda en çok öğrenci (\%2.21) ve dokümanın (\%2.21) tercih edildiği, dil biliminde en çok öğrenci (\%0.88) ve öğretmenin 
(\%0.88) tercih edildiği, güzel sanatlarda en çok öğrenci (\%1.33) ve öğretmenin (1.33) tercih edildiği, spor alanında ise en çok halkın (\%0.88) tercih edildiği görülmüştür. Tüm alanlarda öğrencilerin tercih edildiği tespit edilmiştir. Öğretmen ve sağlık çalışanlarının ise alan çeşitliliği bakımından en az alanda kullanıldığı tespit edilmiştir.

Tablo 4. Araştırma alanlarındaki örneklem sayılarının dağılımı

\begin{tabular}{|c|c|c|c|c|c|c|c|c|c|c|c|c|c|c|}
\hline \multirow[b]{2}{*}{ Alan } & \multicolumn{2}{|c|}{$\begin{array}{l}1-10 \\
\text { aras1 }\end{array}$} & \multicolumn{2}{|c|}{$\begin{array}{l}11-30 \\
\text { aras1 }\end{array}$} & \multicolumn{2}{|c|}{$\begin{array}{l}31-100 \\
\text { aras1 }\end{array}$} & \multicolumn{2}{|c|}{$\begin{array}{l}101-300 \\
\text { aras1 }\end{array}$} & \multicolumn{2}{|c|}{$\begin{array}{l}301- \\
1000 \\
\text { arasi }\end{array}$} & \multicolumn{2}{|c|}{$\begin{array}{l}1000 \text { 'den } \\
\text { fazla }\end{array}$} & \multicolumn{2}{|c|}{$\begin{array}{l}\text { Belirtil- } \\
\text { memiş }\end{array}$} \\
\hline & $\mathrm{N}$ & $\%$ & $\mathrm{~N}$ & $\%$ & $\mathrm{~N}$ & $\%$ & $\mathrm{~N}$ & $\%$ & $\mathrm{~N}$ & $\%$ & $\mathrm{~N}$ & $\%$ & $\mathrm{~N}$ & $\%$ \\
\hline Eğitim & 8 & 3.54 & 17 & 7.52 & 23 & 10.18 & 19 & 8.41 & 9 & 3.98 & 4 & 1.77 & 28 & 12.39 \\
\hline Sağllk & 7 & 3.10 & 13 & 5.75 & 23 & 10.18 & 22 & 9.73 & 4 & 1.77 & 4 & 1.77 & 12 & 5.31 \\
\hline Sosyal Beşeri & 1 & 0.44 & 2 & 0.88 & 2 & 0.88 & 3 & 1.33 & - & - & - & - & 2 & 0.88 \\
\hline Mühendislik & - & - & 1 & 0.44 & - & - & 3 & 1.33 & 1 & 0.44 & - & - & 2 & 0.88 \\
\hline Dil Bilimi & 2 & 0.88 & - & - & - & - & - & - & 1 & 0.44 & 1 & 0.44 & 1 & 0.44 \\
\hline Güzel sanatlar & 1 & 0.44 & 1 & 0.44 & - & - & - & - & - & - & - & - & 2 & 0.88 \\
\hline Spor & 1 & 0.44 & 2 & 0.88 & - & - & - & - & - & - & - & - & - & - \\
\hline Hukuk & - & - & - & - & 1 & 0.44 & - & - & 1 & 0.44 & - & - & 1 & 0.44 \\
\hline Din Bilimi & - & - & - & - & 1 & 0.44 & - & - & - & - & - & - & - & - \\
\hline Toplam & 20 & 8.85 & 36 & 15.93 & 50 & 22.12 & 47 & 20.80 & 16 & 7.08 & 9 & 3.98 & 48 & 21.24 \\
\hline
\end{tabular}

Tablo 4 incelendiğinde uzaktan eğitim alanında video kullanımına yönelik araştırmalarda örneklem sayısı olarak en çok 31-100 arası (\%22.12) tercih edildiği ve çoğu çalışmada (\%21.24) örneklem sayısının belirtilmediği tespit edilmiştir. Bunu sırasıyla 101-300 arası (\%20.80), 11-30 aras1 (\%15.93), $1-10$ aras1 (\%8.85), 301-1000 aras1 (\%7.08) ve 1000'den fazla (\%3.98) takip etmiştir.

Tablo 4 incelendiğinde uzaktan eğitim alanında video kullanımına yönelik yapılan araştırmalardaki alanlardaki örneklem sayılarının dağıl1mında sağlık (\%10.18) alanında ve din bilimi (\%0.44) alanında en çok 31100 arası örneklem sayısının tercih edildiği, eğitim (\%12.39) ve güzel sanatlar (\%0.88) alanında ise en çok örneklem sayısının belirtilmediği çalışmalar tespit edilmiştir. Sosyal beşeri (\%1.33) ve mühendislik (\%1.33) alanlarında ise 101-300 arası örneklem sayısının daha çok tercih edildiği görülmüştür. Dil bilimi (\%0.88) alanında en çok 1-10 arası tercih edilirken, spor (\%0.88) alanında ise 11-30 arası örneklem sayısı tercih edilmiştir. 
Spor ve dil bilimi hariç tüm alanlarda örneklem sayısının belirtilmediği çalışmalar görülmüştür. Çoğu alanda ise 1-10 arası ve 11-30 arası örneklem sayısının daha çok tercih edildiği tespit edilmiştir. 1000'den fazla örneklem sayısının ise alan çeşitliliği bakımından en az alanda kullanıldığ tespit edilmiştir.

\section{Tartışma ve Sonuç}

Teknolojik gelişmelerin gün geçtikçe hızlanması eğitimde de bu uygulamaların fazlaca kullanılmasına neden olmaktadır. Bu gelişmelerin getirdiği materyallerden biri olan videolar özellikle uzaktan eğitimde senkron ve asenkron olarak uygulanmaktadır. Uzaktan eğitim alanında video kullanımına yönelik 2000-2019 yılları arasında yayınlanmış makaleler incelendiğinde Grafik 1'de görüldüğü gibi en çok yayının 2018 ve 2019 yılında yapıldığı tespit edilmiştir. Her iki yılda da 34 makalenin yapıldığı ve 2014 yılından sonra da düzenli bir artışla bunun devam ettiği görülmektedir.

Eğitim kurumları, eğitim süreçlerini geliştirmek ve bilgileri öğrencilerine etkili bir şekilde ulaştırmak için sürekli bir çaba göstermektedirler. Yüzyıllar boyunca eğitim, bu tür görevler için tek yöntem olarak görülen geleneksel yüz yüze eğitim metodunu kullanmıştır. Ancak, modern iletişim teknolojilerinin, özellikle İnternet'in ortaya çıkışı, ders verme faaliyetlerinin uzaklara ulaştırılması için çeşitli araçlar ve materyaller ortaya çıkarmış (Kotevski ve Milenkoski 2018), öğrencilerin öğrenimini geliştirmek için web sayfalarında metin yanında görsel-işitsel materyaller de yayınlanmıştır. Öğretilen konularla ilgili olarak, herkes tarafından erişilebilir kılınan bu materyallere her zaman ve her yerde ulaşım sağlanmıştır (Granjo ve Rasteiro, 2018). Videoların, öğrenme ortamlarının ayrılmaz bir parçası olma noktasına geldiği ve öğrenmede giderek daha fazla kullanıldığı görülmektedir. Buna paralel olarak, İnternetin gelişmesi bilgiye erişimi önemli ölçüde genişletip, video yayınlamayı çok daha kolay hale getirmiştir (Cojean ve Jamet, 2017). Son yıllarda bilgi ve iletişim teknolojilerinin artmasıyla videonun kullanılma olanağının artmasının incelenen makalelerdeki bu artışa neden olduğu söylenebilir.

Uzaktan eğitim alanında video kullanımına yönelik 2000-2019 yılları arasında yayınlanmış makalelerde araştırma alanlarına göre en çok eğitim 
ve sağlık konularının ele alındığı görülmüş̧ür. En az yayının ise spor, hukuk ve din bilimi alanında yapıldığı tespit edilmiştir. Tablo 1'de görüldüğü gibi 108 adet eğitim, 85 adet de sağlık alanında çalışma yapılmış olup ilgili çalışmalarda diğer alanların ise daha az tercih edildiği görülmektedir.

Eğitim konusunda ilk, orta ve yükseköğrenimde özellikle çevrimiçi öğrenmenin devam eden genişlemesiyle birlikte, bu ortamlarda tüm öğrencileri desteklemeye yönelik çalışmalar yapılmıştır. Öğrenmede öğrenci ve eğitmen üzerinde video tasarlamaya ve geliştirmeye yönelik çalışmalar gün geçtikçe artmaktadır (Wang ve Antonenko 2017). Sağlık alanında ise video materyalleri her alanda olduğu gibi tıp alanında da sıkça kullanılmaktadır. Tıp alanında uzmanların, tıp eğitimi alan öğrencilerin ve hatta hastaların dahi video paylaşım sitelerindeki videoları izlediği, bu videolardan bilgi edindiği ya da bilgilerini tazelediği bilinmektedir (Desai vd., 2013). Yapılan çalışmalarda tıp eğitiminde verilen video desteğinin, eğitimde niteliği artırmada önemli adımlardan biri olduğu da görülmektedir (Knowles, Kinchington, Erwin ve Peters, 2014). Videoların sağlık açısından öğrenmede hem temel hem de destek materyaller olarak kullanıldığ görülmektedir.

Uzaktan eğitim alanında video kullanımına yönelik 2000-2019 y1lları arasında yayınlanmış makalelerde en çok nicel yöntemin kullanıldığı görülmüştür. Tablo 1'de görüldüğü gibi 113 çalışmada nicel yöntem en fazla tercih edilen yöntem olurken, en az kullanılan yöntem olarak da 17 çalışmayla alan yazın olmuştur. Uzaktan eğitim alanında video kullanımına yönelik yapılan araştırmalardaki alanlarda kullanılan yöntemlerin dağılımı incelendiğinde sağlık, eğitim ve mühendislik alanlarında daha çok nicel çalışmaların yapıldığı görülmüş̧tür. Sosyal beşeri, güzel sanatlar, hukuk alanlarında daha çok nitel çalışmalar yapıldığı tespit edilmiştir.

İstatistiksel veri analizine dayalı olarak yapılan nicel araştırmaların aksine nitel araştırmalar, daha çok insanların olaylara ne tür anlamlar yükledikleri, başka bir deyişle olayları nasıl niteledikleri sorusuna cevap arayan araştırmalardır (Dey, 2003). Nitel veri analizinin akademik çevrelerde itibar görmeye başlaması, sosyal gerçekliğin betimlenmesi ve açıklanması sürecindeki öneminden gelmektedir. Bundan dolayı bu alanda yapılan çalışmaların sayısında önemli bir artışa yol açtığı da söylenebilir. Ayrıca 
son yıllarda birçok üniversitede lisans ve lisansüstü programlar kapsamında "nitel veri analizi" başlıklı derslerin de verilmeye başladığı görülmektedir (Akt: Özdemir, 2010).

Uzaktan eğitim alanında video kullanımına yönelik 2000-2019 yılları arasında yayınlanmış makalelerde veri toplama aracı olarak en çok anket kullanılmıştır. Tablo 2'de görüldüğü gibi 88 çalışmada anket en fazla tercih edilen araç olurken en az veri toplama yöntemi olarak 16 çalışmayla gözlem olmuştur. Uzaktan eğitim alanında video kullanımına yönelik yapılan araştırmalardaki alanlarda kullanılan veri toplama araçlarının dağılımı incelendiğinde eğitim, sağlık, mühendislik ve hukuk alanında en çok anketin tercih edildiği görülmüştür. Sosyal beşeri alanda en çok doküman ve görüşmenin kullanıldığı tespit edilmiştir.

Anket, varlıkların üyesi olduğu daha büyük popülasyonun niteliklerinin nicel tanımlayıcılarını oluşturmak amacıyla (bir örneklem) kuruluşlardan bilgi toplamak için sistematik bir yöntemdir. "Sistematik" kelimesi kasıtlıdır ve anketleri diğer bilgi toplama yollarından anlamlı bir şekilde ayırır. Tanımda (örneği) ifadesi yer alır çünkü bazen anketler bir popülasyondaki herkesi ve bazen de sadece bir örneği ölçmeye çalışır (Groves, vd., 2011). Özellikle nicel çalışmalarda hem dağıtma, hem de toplama aç1sindan anket kullanımı yaygındır.

Uzaktan eğitim alanında video kullanımına yönelik araştırmalarda örneklem türü olarak en çok öğrenciler tercih edilmiştir. Tablo 3 'te görüldüğü gibi 138 çalışmada öğrenci en fazla tercih edilen örneklem türüdür. Uzaktan eğitim alanında video kullanımına yönelik yapılan araştırmalardaki alanlardaki örneklem türlerinin dağılımı incelendiğinde eğitim, sağlık, mühendislik, hukuk ve din bilimi alanında en çok öğrencilerin tercih edildiği görülmüş̧tür. Uzaktan eğitim alanında video kullanımına yönelik araştırmalarda örneklem sayılarının dağılımı olarak Tablo 4'te görüldüğü gibi en çok 31-100 arası tercih edilmiştir. Örneklem sayılarının dağılımda bu oranların en çok sağlık ve din alanında tercih edildiği görülmektedir.

İyi geliştirilmiş örneklem seçimleri her çalışmanın sağlamlığı için elzemdir (Marshall ve Rosmann, 1999). Örneklem, evreni temsil etmek üzere çeşitli tekniklerle çalışma evreni/nüfusu birimleri içinden seçilen ve üzerinde inceleme yapılan kesit (Taylan, 2015) olarak tarif edilebilir. Yapılan çalışmalarda örneklem olarak öğrencilerin seçilme sebeplerinin en 
önemlilerinden biri videonun uzaktan eğitimde kullanılan önemli materyallerden biri olduğudur.

Uzaktan eğitimde yazılı materyallerin yanında görsel ve işitsel bir materyal olan videoların kullanımı giderek yaygınlaşmaktadır. Alan yazın tarandığında da bu videolara yönelik çalışmaların arttığı görülmektedir. Daha çok etkileşimli, etkileşimsiz, senkron, asenkron videoların tasarım, yayınlanma ortamları ve sürelerine yönelik çalışmalar yapılıp alan yazına katkıda bulunulabilir. 


\title{
EXTENDED ABSTRACT
}

\section{A Review of Articles on Video Usage in Distance Education between 2000 and 2019}

\author{
* \\ Asiye Ata - Melike Arslan \\ Atatürk University
}

Video, which is a visual and audio material used in many places today, has an important place in our lives. With the development of technology, videos have become one of the main sources used in education, as well as in fields such as economy, politics and health. As it is used in all education and training levels, it emerges as one of the important materials especially in open and distance education.

The aim of this study is to reveal the descriptive, methodological and general trends of the researches on the use of video in distance education published in journals covered by SSCI between 2000 and 2019. For this purpose, the study sought to answer the following research question.

The articles published between 2000-2019 on the use of video in the field of distance education

1. What is the distribution by years?

2. What is the distribution of the methods used in the research areas?

3. What is the distribution of data collection tools in research areas?

4. What is the sample type and distribution of sample numbers in the research areas?

In the study, content analysis method was used in order to reveal general trends in the use of video in distance education. The sample of the study focused on articles on the use of video in distance education. In order to reach the articles, a subject-focused search with the words "distance education" and "video" was made in the database of "Web of Science". The year range 2000-2019 was selected in the search and only the Social Science Citation Index (SSCI) was selected among the citation indexes. 338 studies were listed in the search results. When only the articles were considered, the ones whose full text could not be reached and the studies on the use of video in distance education were excluded, analyzes were carried out on 226 articles. 
In the study, the method and sample number sections included in the Educational Technologies Classification Form (Göktaş et al. 2012) as a Data Collection Tool were taken and descriptive information, research area, sample and conclusion sections were added within the scope of the research purpose and a form specific to the study was created.

In data analysis, analyzes were carried out on the basis of the year of the articles, research areas, method, data collection tools, sampling, and the number of samples in line with the study purpose. Accordingly, the data are presented using descriptive statistical methods.

In the findings, it was observed that the studies on the use of video in distance education have increased in the last 5 years. It is seen that the least publications were made in 2006, and the most in 2018 and 2019.

It is seen that the use of video in the field of distance education is mostly used in the field of education (47.79\%), followed by health $(37.61 \%)$ and social humanities $(4.42 \%)$ areas.

In studies on the use of video in the field of distance education, quantitative methods were preferred $(50.00 \%)$, followed by qualitative methods (30.53\%), mixed methods (11.95\%) and literature $(7.52 \%)$.

When the distribution of the methods used in the researches on the use of video in the field of distance education was examined, it was seen that the number of quantitative studies in the field of health was the highest (24.34\%). When all fields were examined, it was observed that more quantitative studies were conducted in the fields of health $(24.34 \%)$, education (19.91\%) and engineering (2.21\%). It was determined that more qualitative studies were conducted in the fields of social humanities $(2.65 \%)$, fine arts $(1.77 \%)$ and law $(0.88 \%)$.

In studies on the use of video in the field of distance education, the most common data collection tool was questionnaire (38.94\%). This was followed by document (23.01\%), interview $(20.80 \%)$, attitude scale $(18.58 \%)$, and achievement test $(11.50 \%)$. It was determined that the least used data collection tool was observation (7.08\%).

When examining the distribution of data collection tools used in the fields of video use in the field of distance education, it was seen that the questionnaire was the most preferred in the fields of education $(19.47 \%)$, health $(15.49 \%)$, engineering $(1.77 \%)$ and law $(0.88 \%)$. In the field of social humanities, the most documents (1.77\%) and interviews (1.77\%) are used, 
the most questionnaires $(0.88 \%)$ and documents $(0.88 \%)$ are used in linguistics, and the most documents $(1.33 \%)$ are used in the fine arts. $(0.88 \%)$ and achievement test $(0.88 \%)$ were used, and in the field of religion science, the interview $(0.44 \%)$ and attitude scale $(0.44 \%)$ were used the most.

In studies on the use of video in distance education, students $(61.06 \%)$ were the most preferred sample type. This was followed by documents $(12.83 \%)$, public $(12.39 \%)$, teachers $(9.73 \%)$ and healthcare workers (9.73\%).

In the distribution of the sample types in the researches on the use of video in the field of distance education, it was observed that students were the most preferred in the fields of education (33.19\%), health $(18.58 \%)$, engineering $(3.10 \%)$, law $(0.88 \%)$ and religious science $(0.88 \%)$. Students $(2.21 \%)$ and documents $(2.21 \%)$ are most preferred in social humanities, students $(0.88 \%)$ and teachers $(0.88 \%)$ are the most preferred in linguistics, students $(1.33 \%)$ and teachers $(1.33 \%)$ are the most preferred in fine arts is preferred, and in the field of sports, the people $(0.88 \%)$ are the most preferred. It has been determined that students are preferred in all areas.

In studies on the use of video in the field of distance education, it was determined that $31-100(22.12 \%)$ were the most preferred sample size. It was followed by 101-300 (20.80\%), 11-30 (15.93\%), 1-10 (8.85\%), 301-1000 $(7.08 \%)$ and more than $1000(3.98 \%)$ respectively.

In the distribution of the sample numbers in the researches on the use of video in the field of distance education, in the field of health $(10.18 \%)$ and in the field of religious science $(0.44 \%)$, the sample size between 31 and 100 is preferred. In the field of education (12.39\%) and fine arts $(0.88 \%)$, it was determined that the studies with the highest sample size were not specified. It was observed that the sample size between 101-300 was preferred more in the fields of social humanities $(1.33 \%)$ and engineering $(1.33 \%)$. While 1-10 was preferred in the field of linguistics $(0.88 \%)$, the sample size between $11-30$ was preferred in the field of sports $(0.88 \%)$. 


\section{Kaynakça / References}

Abeysekera, L. and Dawson, P. (2015). Motivation and cognitive load in the flipped classroom: Definition, rationale and a call for research. Higher Educatio Research \& Development, 34(1), 1-14.

Bijnens, M., Vanbuel, M., Verstegen, S., and Young, C. (2004). Handbook on digital video and audio in education-creating and using audio and video material for education purposes. Published by The VideoAktiv Project Socrates Minerva.

Brecht, H., and Ogilby, S. (2008). Enabling a comprehensive teaching strategy: Video lectures. Journal of Information Technology Education: Innovations in Practice, 7(1), 71-86.

Cojean, S., and Jamet, E. (2017). Facilitating information-seeking activity in instructional videos: The combined effects of micro-and macroscaffolding. Computers in Human Behavior, 74, 294-302.

Dabbagh, N., and Bannan-Ritland, B. (2005). Online learning: Concepts, strategies and application. Upper Saddle River, New Jersey, Pearson Merrill Prentice-Hall.

Desai, T., Shariff, A., Dhingra, V., Minhas, D., Eure, M., ve Kats, M. (2013). Is content really king? An objective analysis of the public's response to medical videos on YouTube. PLoS One, 8(12), e82469.

Dey, I. (2003). Qualitative data analysis: A user friendly guide for social scientists. Routledge.

Eryılmaz, M., and Jaballa, R. (2019). Öğrenme stillerine göre kişiselleştirilmiş çevirimiçi öğrenme ortamları için bir model önerisi. Turkish StudiesInformation Technologies and Applied Sciences, 14(2), 179-192.

Garzon, S. A. (2012). The impact of the audiovisual aids in the teaching learning process at the technical university of cotopaxi during the academic period March-July 2012. (Doctorate Thesis). Technical University of Cotopaxi.

Goktas, Y., Kucuk, S., Aydemir, M., Telli, E., Arpacik, O., Yildirim, G., ve Reisoglu, I. (2012). Educational technology research trends in Turkey: A content analysis of the 2000-2009 decade. Educational Sciences: Theory E Practice, 12(1), 177-199.

Granjo, J. F., and Rasteiro, M. G. (2018). LABVIRTUAL-A platform for the teaching of chemical engineering: The use of interactive videos. Computer Applications in Engineering Education, 26(5), 1668-1676. 
Groves, R. M., Fowler Jr, F. J., Couper, M. P., Lepkowski, J. M., Singer, E., and Tourangeau, R. (2011). Survey methodology (Vol. 561). John Wiley and Sons.

Halls, J. (2012). Rapid video development for trainers: How to create learning videos fast and affordably. Alexandria, ASTD Press.

Knowles, C., Kinchington, F., Erwin, J., and Peters, B. (2001). A randomised controlled trial of the effectiveness of combining video role play with traditional methods of delivering undergraduate medical education. Sexually Transmitted Infections, 77(5), 376-380.

Kotevski, Z., and Milenkoski, A. (2018). Are free internet technologies and services the future of synchronous distance learning?. Turkish Online Journal of Distance Education, 19(3), 4-14.

Ma, L. (2019). Research on distance education image correction based on digital image processing technology. EURASIP Journal on Image and Video Processing, 2019(1), 18.

Marshall, C., and Rossman, G. B. (2014). Designing qualitative research. Sage publications.

Özdemir, M. (2010). Nitel veri analizi: Sosyal bilimlerde yöntembilim sorunsalı üzerine bir çalışma. Eskişehir Osmangazi Üniversitesi Sosyal Bilimler Dergisi, 11(1), 323-343.

Singh, A. K., Nag, A., Karforma, S., and Mukhopadhyay, S. (2019). Implementation of multi-agent based Digital Rights Management System for Distance Education (DRMSDE) using JADE. International Journal of Advanced Computer Science and Applications,10(3),343-352.

Taylan, A. (2015). Nitel ve nicel araştırmalarda evren ve örneklem seçimi ve sorunlar. B. Ylldırım (Ed.), İletişim araştırmalarında yöntemler. Konya: Literatürk, 47-83.

Wang, J., and Antonenko, P. D. (2017). Instructor presence in instructional video: Effects on visual attention, recall, and perceived learning. Computers in human behavior, 71, 79-89.

Yıldırım, A., ve Şimşek, H. (2006). Sosyal bilimlerde nitel araştırma yöntemleri. Seçkin Yayıncilık.

Yılmaz, M., ve Üredi, L. (2020). İlkokul öğretmenlerinin eğitimde teknoloji kullanımına ilişkin bilgisayar yeterliliklerinin değerlendirilmesi. OPUS Uluslararası Toplum Araştırmaları Dergisi, 16(32), 4723-4742. 
Zhang, D., Zhou, L., Briggs, R. O., and Nunamaker Jr., J. F. (2006). Instructional video in e-learning: Assessing the impact of interactive video on learning effectiveness. Information \& Management, 43(1), 15-27.

\section{Kaynakça Bilgisi / Citation Information}

Ata, A. ve Arslan, M. (2021). 2000-2019 yılları arasında uzaktan eğitimde video kullanımı üzerine yapılan makalelerin incelenmesi. OPUSUluslararası Toplum Araştırmaları Dergisi, 18(40), 2480-2499. DOI: 10.26466/opus.864252. 